\title{
Nutrient intake by duration of ex-smoking in the Scottish Heart Health Study
}

\author{
BY CAROLINE BOLTON-SMITH, MARK WOODWARD, COLIN A. BROWN \\ AND HUGH TUNSTALL-PEDOE \\ Cardiovascular Epidemiology Unit, University of Dundee, Ninewells Hospital and Medical School, \\ Dundee DDI $9 S Y$
}

(Received 27 September 1991 - Accepted 12 March 1992)

\begin{abstract}
Information on current-, never- and ex-smokers (including duration of cessation) was obtained in a crosssectional survey of risk factors for coronary heart disease (CHD), the Scottish Heart Health Study. Diet was also assessed by food frequency questionnaire in a total of $\mathbf{4 2 6 5}$ men and $\mathbf{4 7 7 0}$ women. Nutrient intakes were computed by sex and smoking group and, according to their diet, the ex-smokers were categorized as current- or never-smokers using discriminant analysis techniques.

The current- and five ex-smoking groups differed negligibly in past smoking characteristics. Energyadjusted intake of polyunsaturated fat, fibre and the antioxidant vitamins were lowest in currentsmokers, and for men, intakes increased progressively with duration of ex-smoking to reach the level of never-smokers. In a similar manner, energy, sugar and alcohol decreased with duration of ex-smoking. Fewer trends were observable for women, and the diets of ex-smokers more immediately resembled that of never-smokers.

Discriminant analysis for the combined nutrients correctly categorized 72 and $69 \%$ of male, and 66 and $65 \%$ of female current- and never-smokers respectively. By 4 years of smoking cessation the general dietary pattern of ex-smokers was similar to never-smokers for both sexes. Whether this represents a change in diet over time or a cohort effect is unclear, but the results do suggest that the apparent healthier diet of ex-smokers may contribute to their reduction in CHD risk compared with life-long currentsmokers.
\end{abstract}

Antioxidant vitamins: CHD risk: Discriminant analysis: Ex-smokers: Nutrient intake

Smoking is recognized as one of the major risk factors for coronary heart disease (CHD), lung cancer and other respiratory diseases (US Office on Smoking and Health, 1979). Diet may also influence incidence of CHD by modulating blood cholesterol levels (e.g. saturated fat, fibre and cholesterol; Gurr et al. 1989; Bolton-Smith et al. 1991 d) and by reducing freeradical-mediated tissue damage (the antioxidant vitamins A, C and E; Duthie et al. 1989; Gey et al. 1991).

The increased risk of CHD from smoking has been variously reported to be negligible in ex-smokers (Doll et al. 1980; Willett et al. 1987; Gramenzi et al. 1989); to be mitigated within 2-3 years (Rosenberg et al. 1985, 1990), within 5 years (Doll \& Peto, 1976), or more generally within 10 years of cessation, in all but life-long heavy smokers (US Office on Smoking and Health, 1983). Some information is available on the changes in other risk factors which may occur on cessation of smoking from longitudinal and cross-sectional studies (Gordon et al. 1975; Kato et al. 1989). However, generally the literature addresses the socio-environmental and demographic characteristics of people who quit $v$. people who continue smoking, with little information on the effect of duration of quitting (West et al. 1977; Friedman et al. 1979; Ockene et al. 1985; Kaprio \& Koshenvuo, 1988).

Diet may be one of the risk factors which alters with smoking cessation, for smoking 
affects taste preferences (e.g. Grunberg, 1982) and quitters tend to have an improved health consciousness (West et al. 1977). Although numerous studies have examined the diets of current- and never-smokers (Whichelow et al. 1980; Fisher \& Gordon, 1985; Fulton et al. 1988; Klesges et al. 1990) and some have included ex-smokers as a separate group (Fehily et al. 1984; Hebert \& Kabat, 1990; Bolton-Smith et al. 1991 c), it appears that Lincoln (1969) and Kato et al. (1989) are the only people to have previously reported dietary habits according to duration of ex-smoking.

Prospective studies of smoking and ex-smokers have problems with classification and recidivism (Rosenberg et al. 1990) and intervention studies have problems with success rate, classification and deception, e.g. the Multiple Risk-Factor Intervention Trial (MRFIT; Jarvis et al. 1984). Although cross-sectional studies are also far from ideal for looking at trends in ex-smokers (for group differences may be cohort effects rather than the effects of smoking per se), this type of data is more easily available. So long as group characteristics are compared and provisos made, the information obtained from cross-sectional studies (such as the baseline survey of the Scottish Heart Health Study (SHHS; Smith et al. 1989)) may be usefully interpreted.

In the SHHS, socio-demographic and full smoking details were elicited from a random sample of middle-aged men and women. (The biochemical markers of smoking, serum cotinine and expired air CO were also measured.) A preliminary report from the SHHS presented nutrient intakes of current, never- and ex-smokers (Bolton-Smith et al. 1991 c). It illustrated that the diets of ex-smokers were generally more similar to those of neversmokers than current-smokers. However, the ex-smokers were not a homogeneous group, for the period of abstention ranged from less than 6 months to 50 years. The sample size (10359) in the SHHS is sufficiently large to allow sub-division of ex-smokers according to duration, and comparison to be made with current- and never-smokers. Thus, in order to assess the possible contribution from diet to the reduction in CHD risk (which is reported to occur) on cigarette quitting, the effect of duration of ex-smoking on diet is examined.

\section{SUBJECTS AND METHODS}

Current-smokers (people smoking at least one cigarette per d), never-smokers and exsmokers (ex-regular smokers in groups 1-5 according to duration of quitting: (1) less than 6 months, (2) 6-11 months, (3) 1-4 years, (4) 5-9 years and (5) 10 or more years) were identified from questionnaire data which were collected in the SHHS. This was a baseline cross-sectional study of 10359 Scottish men and women aged 40-59 years. The full protocol has been reported previously (Smith et al. 1989; Tunstall-Pedoe et al. 1989). Current cigar and pipe smokers were excluded from all the groups except the current (cigarette)-smoking group. Those people who reported to be on a medically prescribed diet were also excluded from these analyses.

Diet was assessed by a food-frequency questionnaire (Yarnell et al. 1983) which included questions on the weekly consumption of fifty food items or groups and the weekly family consumption of butter, margarine, vegetable oils, cheese, cream and table sugar. Alcohol was assessed by a $7 \mathrm{~d}$ recall question. Mean daily nutrient intakes were calculated by a computer program using standard portion sizes and the McCance and Widdowson food tables (Paul \& Southgate, 1978). Details of the use and validations of the food-frequency questionnaire in this population have been reported previously (Bolton-Smith \& Milne, 1991; Bolton-Smith et al. $1991 a, b)$.

\section{Statistical analysis}

Skewed nutrient distributions were normalized by appropriate natural logarithm, square root or arcsine square root transformations before analysis. Energy-adjusted mean daily 
nutrient intakes (percentage of energy) and nutrient densities (amounts per 4.2 MJ $(1000 \mathrm{kcal}))$ are expressed inclusive of energy from alcohol. The untransformed mean values and standard deviations are presented (Tables) or means with their standard errors (Figures). Differences between the current- and never-smoking groups and between the five ex-smoking groups were tested for significance by analysis of covariance. The covariates were age and social class according to occupation (Office of Population Censuses and Surveys, 1980), with women being classified according to their husbands' occupation and the unemployed by their last job.

The ability of the nutrients to discriminate between current- and never-smokers was assessed by linear discriminant analysis for men and women separately. This was done by entering all the dietary variables into the analysis and using a stepwise method with a cutoff value of four for the $F$ statistic when maximizing the Mahalanobis distance between groups (Morrison, 1975). The discriminant function was then used to classify ex-smokers (in groups 1-5) as 'current-smokers' or 'never-smokers'. The percentage allocation for each ex-smoking group was assessed for significant difference from $50 \%$ by the method of least significant difference. Individual nutrients were treated similarly (without the stepwise approach).

\section{RESULTS}

According to the current criteria, satisfactory smoking and dietary information were obtained from 4770 women and 4265 men. The numbers and selected characteristics of the smoking groups are given in Table 1. The median durations of ex-smoking were: group 1, 3 months; group 2, 9 months; group 3,2 years; group 4,7 years for men and 6 years for women; group 5, 18 years. The majority ( $58 \%$ men, $52 \%$ women) of ex-smokers quit 10 or more years ago, and a greater percentage of women $(13.2)$ than men $(7.6 \%)$ reported a duration of abstention of less than 1 year. Neither the maximum number of cigarettes smoked daily nor the number of years of smoking appeared to differ greatly between the current-smokers and the ex-smokers of up to 10 years duration. The median age at which people started smoking was 18 years for women in all smoking groups and also for men who quit 6-11 months ago. For male current-smokers and ex-smokers of $<6$ months and $5-9$ years the median starting age was 16 years, and for the remaining two ex-smoking groups it was 17 years.

Manual occupation predominated in the current-smoking group for both sexes. Median cotinine levels in all ex-smoking groups were low. However, when the number of 'biochemical deceivers' was estimated, by taking those individuals with serum cotinine levels $>17.5 \mathrm{ng} / \mathrm{ml}$ and expired air CO levels $>6 \mathrm{ppm}$ (Woodward \& Tunstall-Pedoe, 1992), the percentage falling into this category for male ex-smoking groups $1-5$ were $12,8 \cdot 3$, $2 \cdot 4,1 \cdot 2$ and 0.6 respectively. For women, the corresponding values were $7 \cdot 8,6 \cdot 7,3.6,1.9$ and $08 \%$. No differences occurred between the ex-smoking groups in the percentage reporting serious illness (angina, heart attack, hypertension, stroke or diabetes) for men or women, although the current- and ex-smokers (as a single group) reported a higher incidence of angina, heart attack and hypertension than did never-smokers. Body mass index (BMI; $\mathrm{kg} / \mathrm{m}^{2}$ ) was lower in current- than never-smokers, and tended to increase with duration of ex-smoking. A greater percentage of ex-smokers reported to be on self-prescribed slimming diets (the exclusion criteria included medically-prescribed slimmers). The percentages slimming for male current-, ex-(1-5) and never-smoking groups were $1 \cdot 8,3 \cdot 4,2 \cdot 7,10 \cdot 2,7 \cdot 9$, $5 \cdot 1$ and $2 \cdot 7$ respectively, and the corresponding values for women were $8 \cdot 8,14 \cdot 3,19 \cdot 6,17 \cdot 1$, $15 \cdot 6,16 \cdot 5$ and $12 \cdot 5$ respectively.

Tables 2 and 3 show the mean total energy and amounts of nutrients consumed daily by smoking group for men and women. Significance levels for differences between current- and 
Table 1. Characteristics of the smoking groups

[Mean or median values with standard (SD) or quartile (QD) deviations respectively]

\begin{tabular}{|c|c|c|c|c|c|c|c|}
\hline \multirow[b]{2}{*}{ Smoking group ... } & \multirow[b]{2}{*}{ Current } & \multicolumn{5}{|c|}{ Ex-smokers* } & \multirow[b]{2}{*}{ Never } \\
\hline & & 1 & 2 & 3 & 4 & 5 & \\
\hline \multicolumn{8}{|l|}{ Men } \\
\hline$n \dagger$ & 1920 & 58 & 36 & 167 & 252 & 710 & 1122 \\
\hline \multicolumn{8}{|l|}{ Age (years) } \\
\hline Mean & $49 \cdot 3$ & $49 \cdot 3$ & $50 \cdot 3$ & $50 \cdot 1$ & $49 \cdot 9$ & $51 \cdot 1$ & $49 \cdot 1$ \\
\hline SD & $5 \cdot 7$ & $5 \cdot 4$ & $6 \cdot 2$ & $5 \cdot 8$ & 5.9 & 58 & $5 \cdot 6$ \\
\hline Manual occupation (\%) & 69 & 55 & 65 & 53 & 60 & 48 & 46 \\
\hline \multicolumn{8}{|l|}{ Serum cotinine $(\mathrm{ng} / \mathrm{ml})$} \\
\hline Median & 284 & $6 \cdot 5$ & $1 \cdot 8$ & $1 \cdot 6$ & 0.5 & $0 \cdot 4$ & $0 \cdot 6$ \\
\hline QD & 95 & 25 & $7 \cdot 5$ & $2 \cdot 5$ & $1 \cdot 5$ & $1 \cdot 4$ & 1.5 \\
\hline \multicolumn{8}{|l|}{$\begin{array}{l}\text { Maximum no. of } \\
\text { cigarettes smoked }(/ d)\end{array}$} \\
\hline Median & 20 & 20 & 25 & 20 & 20 & 20 & - \\
\hline QD & 10 & 13 & 9 & 10 & 11 & 10 & - \\
\hline \multicolumn{8}{|l|}{ No. of years smoked } \\
\hline Median & $32 \cdot 0$ & $32 \cdot 5$ & $31 \cdot 0$ & $31 \cdot 0$ & $28 \cdot 0$ & $15 \cdot 0$ & 0 \\
\hline QD & $10 \cdot 0$ & $12 \cdot 3$ & $15 \cdot 0$ & $11 \cdot 0$ & $11 \cdot 0$ & $13 \cdot 0$ & 0 \\
\hline \multicolumn{8}{|l|}{ BMI $\left(\mathrm{kg} / \mathrm{m}^{2}\right)$} \\
\hline Mean & 25,4 & $25 \cdot 6$ & $26 \cdot 8$ & $27 \cdot 4$ & $27 \cdot 1$ & $26 \cdot 4$ & $26 \cdot 3$ \\
\hline SD & $3 \cdot 0$ & $3 \cdot 2$ & $3 \cdot 7$ & $3 \cdot 6$ & $3 \cdot 0$ & $3 \cdot 1$ & $3 \cdot 2$ \\
\hline \multicolumn{8}{|l|}{ Women } \\
\hline$n^{\dagger}$ & 1844 & 77 & 45 & 169 & 154 & 480 & 2001 \\
\hline \multicolumn{8}{|l|}{ Age (years) } \\
\hline Mean & $49 \cdot 2$ & $49 \cdot 2$ & $49 \cdot 0$ & $50 \cdot 3$ & $49 \cdot 0$ & $49 \cdot 9$ & $49 \cdot 5$ \\
\hline SD & $5 \cdot 8$ & $6 \cdot 2$ & 6.8 & $5 \cdot 8$ & $6 \cdot 0$ & $6 \cdot 1$ & $5 \cdot 7$ \\
\hline Manual occupation (\%) & 64 & 42 & 40 & 45 & 45 & 39 & 47 \\
\hline \multicolumn{8}{|l|}{ Serum cotinine $(\mathrm{ng} / \mathrm{ml})$} \\
\hline Median & 243 & $2 \cdot 7$ & $1 \cdot 3$ & $1 \cdot 1$ & 0.02 & 0.01 & 0.01 \\
\hline QD & 93 & $3 \cdot 3$ & $1 \cdot 8$ & 16 & $1 \cdot 3$ & $1 \cdot 0$ & 0.9 \\
\hline \multicolumn{8}{|l|}{$\begin{array}{l}\text { Maximum no. of } \\
\text { cigarettes smoked }(/ d)\end{array}$} \\
\hline Median & 18 & 18 & 15 & 20 & 15 & 10 & - \\
\hline QD & 8 & 5 & 5 & 5 & 5 & 8 & - \\
\hline \multicolumn{8}{|l|}{ No. of years smoked } \\
\hline Median & 30 & $29 \cdot 0$ & $28 \cdot 0$ & $29 \cdot 0$ & $23 \cdot 0$ & $12 \cdot 0$ & 0 \\
\hline $\mathrm{QD}$ & $11 \cdot 0$ & $12 \cdot 0$ & $16 \cdot 0$ & $11 \cdot 0$ & $10 \cdot 5$ & $13 \cdot 0$ & 0 \\
\hline \multicolumn{8}{|l|}{ BMI $\left(\mathrm{kg} / \mathrm{m}^{2}\right)$} \\
\hline Mean & $25 \cdot 1$ & $25 \cdot 9$ & $25 \cdot 6$ & $26 \cdot 2$ & $26 \cdot 2$ & $25 \cdot 2$ & $26 \cdot 1$ \\
\hline $\mathrm{SD}$ & $4 \cdot 1$ & $5 \cdot 4$ & $3 \cdot 4$ & $4 \cdot 3$ & $4 \cdot 7$ & $4 \cdot 1$ & $4 \cdot 2$ \\
\hline
\end{tabular}

BMI, body mass index (weight $/$ height $^{2}$ ).

* Grouped according to duration of ex-smoking: 1 , <6 months; 2, 6-11 months; 3, 1-4 years; 4, 5-9 years; $5, \geqslant 10$ years.

$\dagger$ No. for which nutrient results were also available: $n$ varied slightly for different variables.

never-smokers and between the ex-smoking groups as measured by analysis of covariance (adjusting for age and social class) are given for these values and for the respective energyadjusted values which are presented in Fig. 1. These plots illustrate the differences in energy-adjusted nutrient intakes between the sexes and between the smoking groups. Downwards trends occurred (from current-smokers through the five ex-smoking groups to never-smokers) for total energy and the percentage energy from sugar for men, and for cholesterol (mg/4.2 MJ) for women. An upwards trend occurred for the percentage energy 


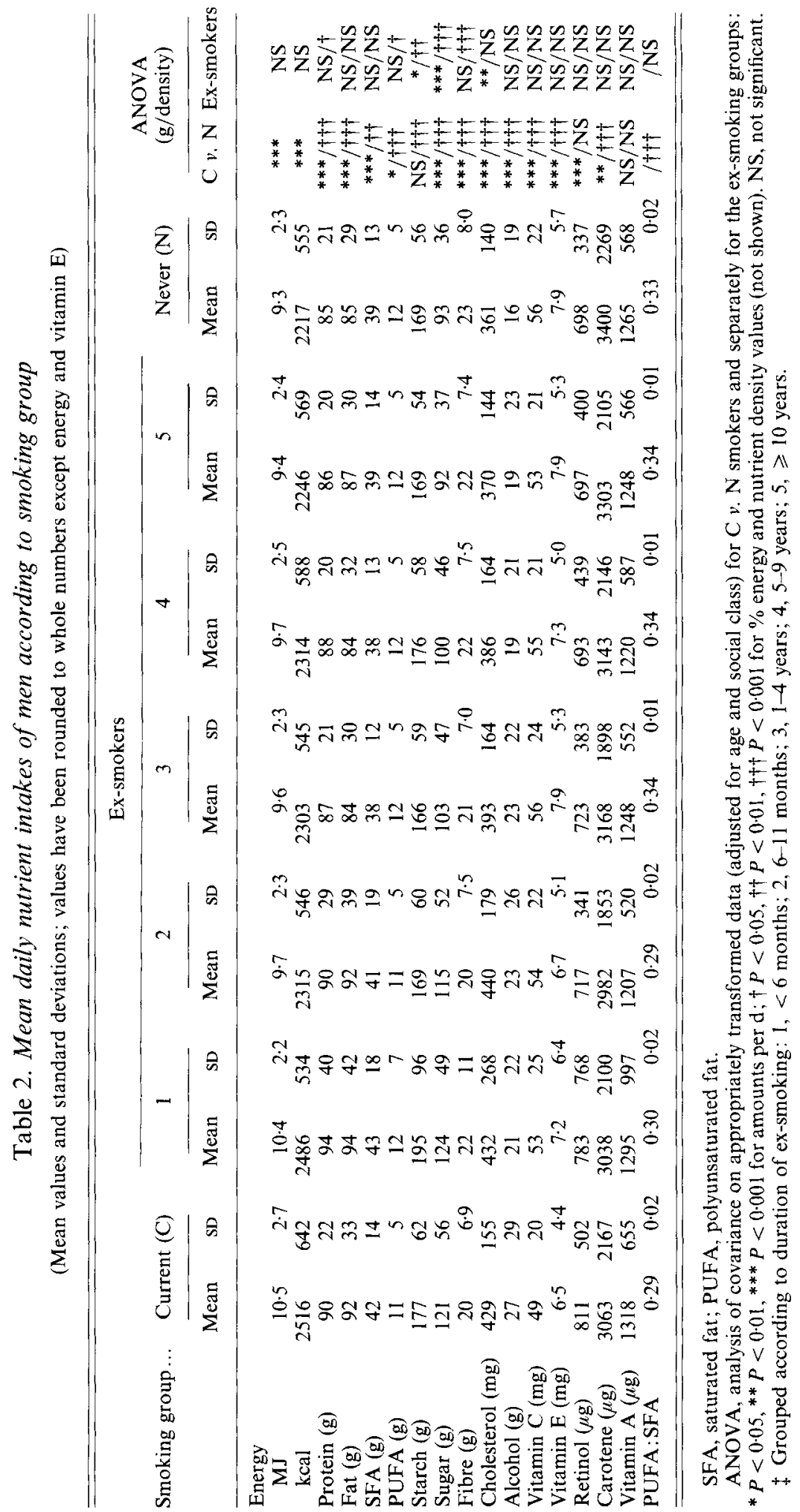




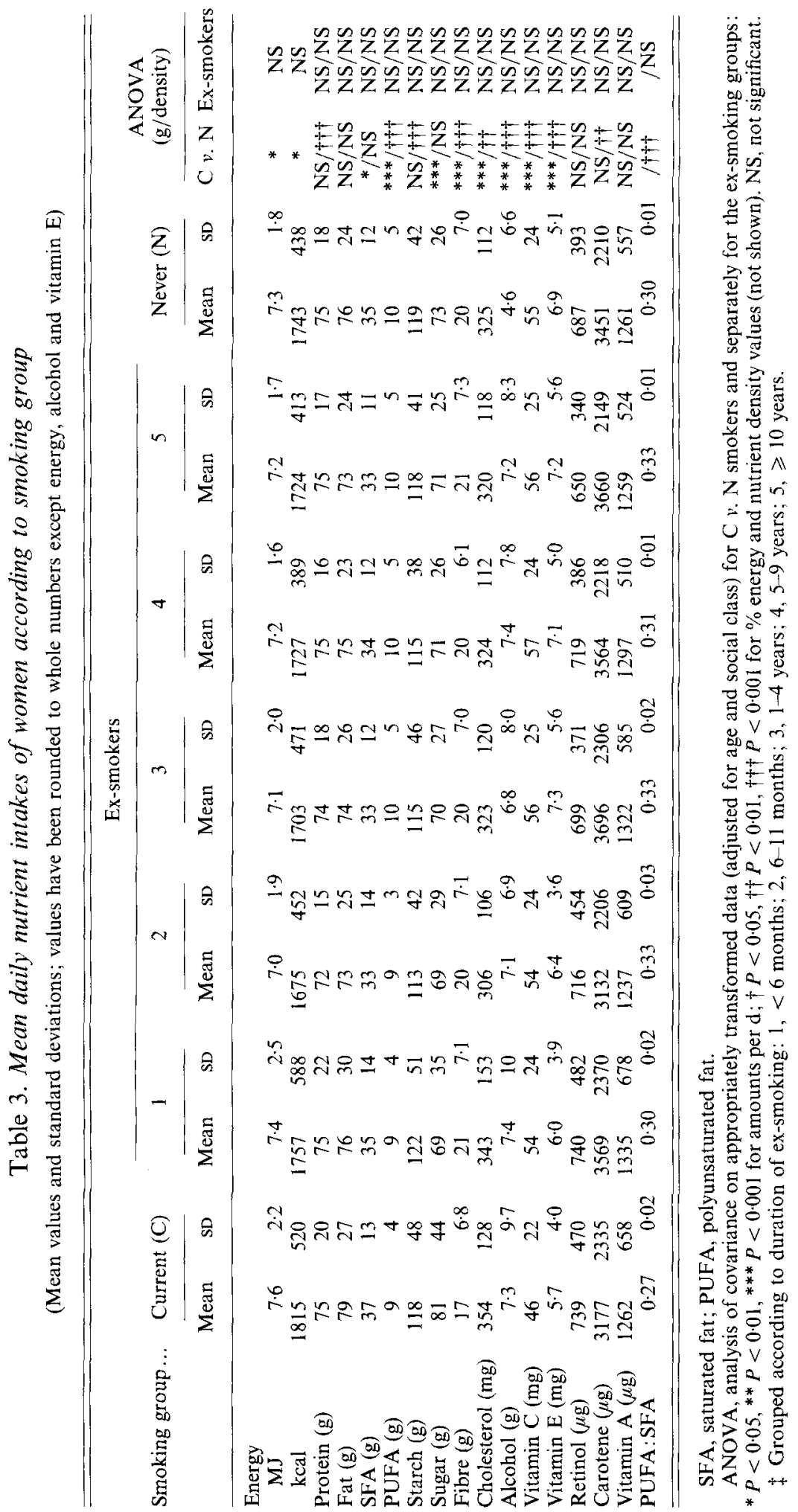



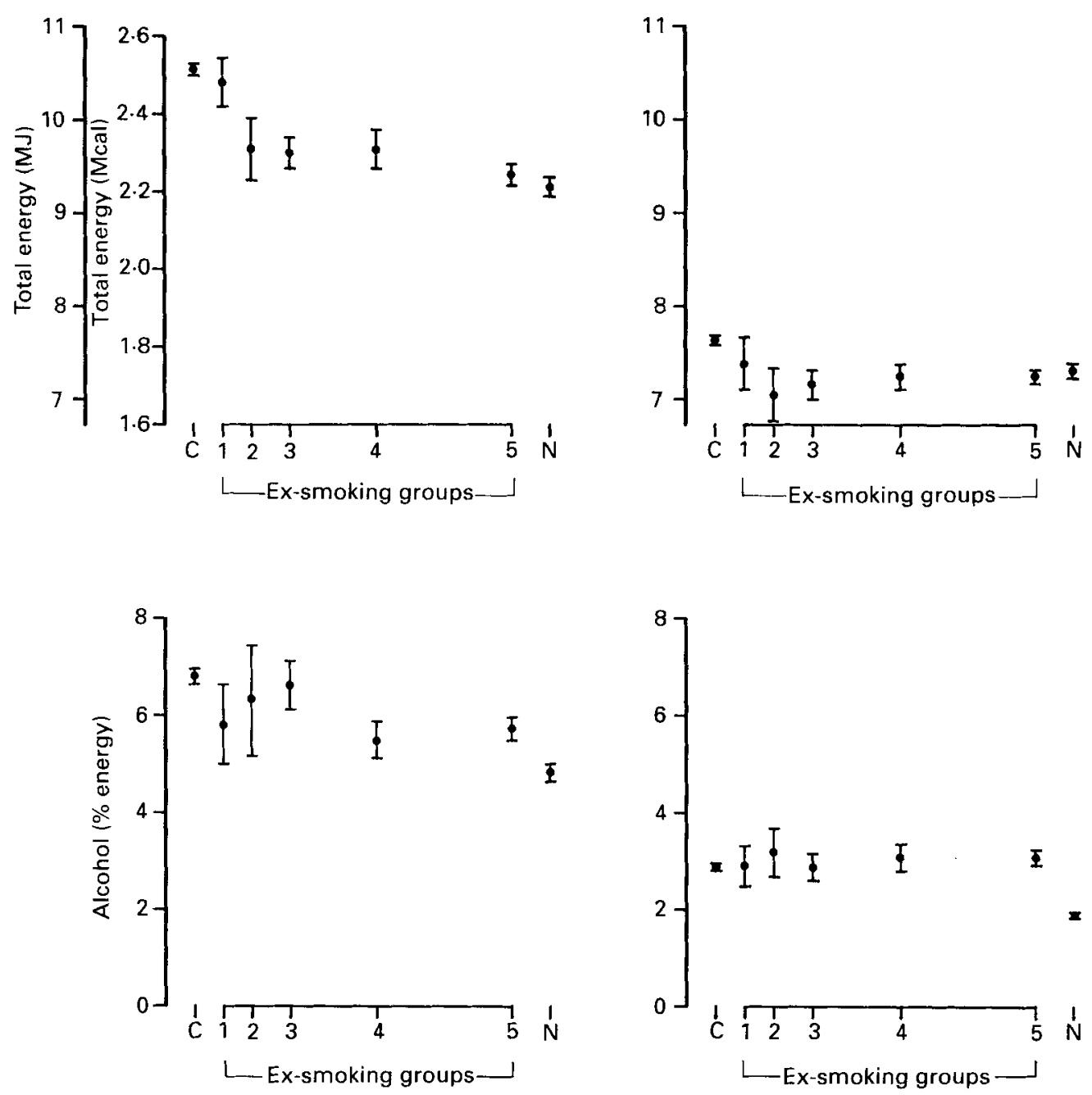

Fig. 1. (continued on pp. 322-327). Energy-adjusted nutrient intakes according to smoking group. Macronutrients expressed as percentage energy and other nutrients expressed on a per $4.2 \mathrm{MJ}$ ( $1000 \mathrm{kcal}$ ) basis, inclusive of alcohol. Ex-smoking groups: 1, <6 months; 2, 6-11 months; 3, 1-4 years; 4, 5-9 years; 5, $\geqslant 10$ years. Median duration of ex-smoking for each group plotted: 1,3 months; 2,9 months; 3,2 years; 4,7 years for men and 6 years for women; 5, 18 years. For statistical significance of differences (by analysis of covariance) between the current (C)- and never (N)-smoking groups, and between the ex-smoking groups, see Tables 2 and 3 for men and women respectively. Values are means with their standard errors represented by vertical bars. (For visual approximation; where the standard error bars do not overlap, statistical significance $(P<0.05)$ is likely. For details of subjects and groups, see Table 1 and p. 316. PUFA, polyunsaturated fatty acids; SFA, saturated fatty acids.

from protein and the nutrient densities for fibre and carotene for men, and for the percentage of energy from polyunsaturated fatty acids and the nutrient densities for vitamin $\mathrm{C}$ and $\mathrm{E}$ for both men and women.

The decline in energy intake from current-smokers through to never-smokers for men is not entirely a result of the declining alcohol consumption across these same groups: the 

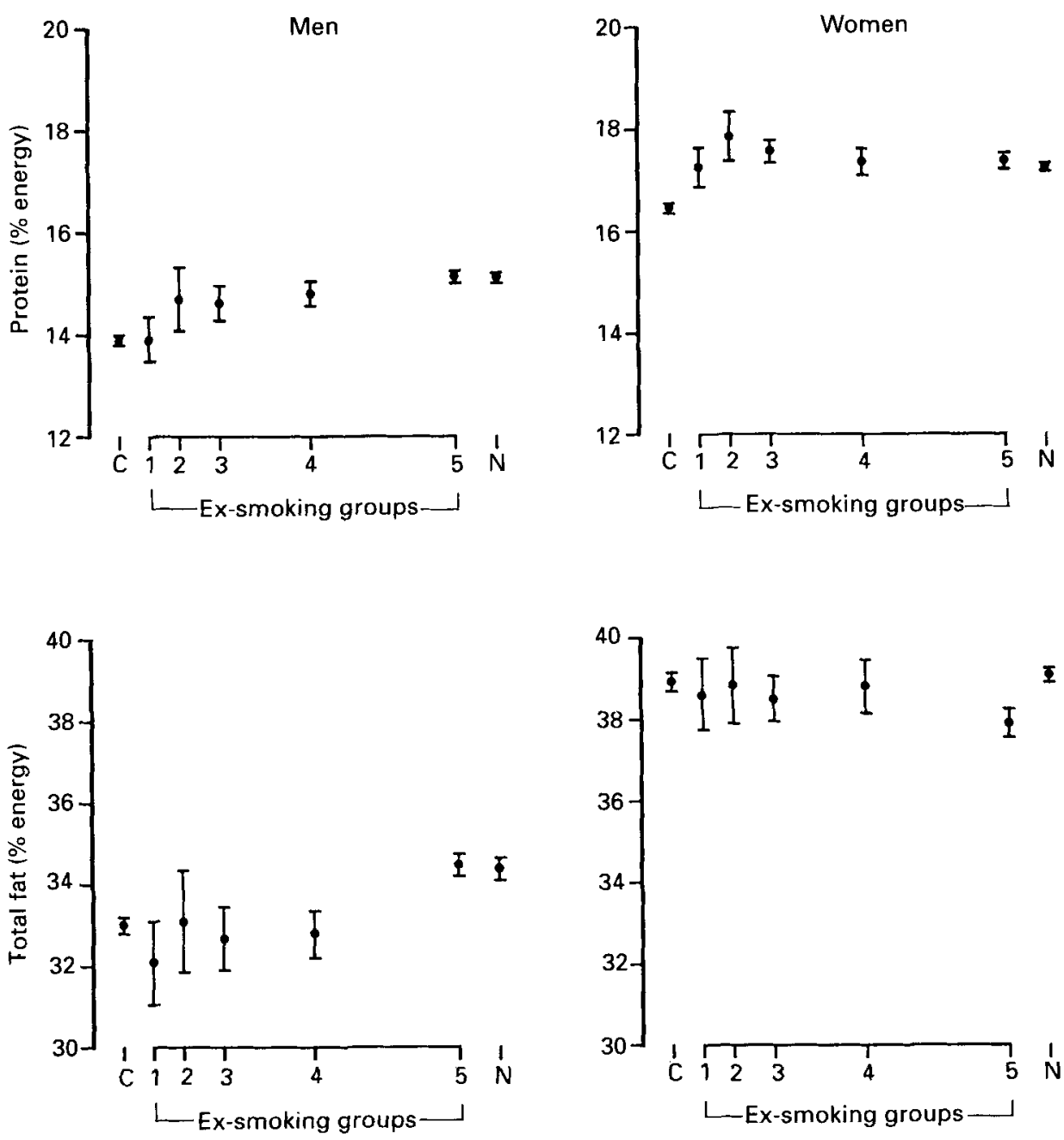

Fig. 1. (contd.). For legend see p. 321.

trends in nutrient intakes are maintained when energy from alcohol is excluded (results not shown). For men, the percentage of the energy change which can be attributed to decreased intake of alcohol for the ex-smoking groups $2-5$ are respectively $13 \cdot 9,13 \cdot 1,27 \cdot 7$ and $25 \cdot 8$. The lower sugar consumption in men according to duration of ex-smoking accounts for more of the energy difference $(11 \cdot 2,31 \cdot 7,39 \cdot 0,40 \cdot 3$ and $35.1 \%$ in the ex-smoking groups 2-5 and never-smokers respectively). For women, alcohol consumption does not decrease on quitting but $26.1 \%$ of the energy difference between current- and never-smokers can be attributed to lower alcohol intake.

The percentage of non-tea and non-coffee drinkers and the percentage who consume at least six cups per $d$ of each are shown in Table 4 by smoking group. The median number of cups of tea and coffee reported to be drunk per $d$ (excluding the non-drinkers) is also given. The results of chi-square tests between the ex-smoking groups are given. For men, heavy coffee drinking was less prevalent in ex-smokers of at least 5 years duration, while for women the ex-smokers of 6-11 months duration drank appreciably more coffee than those in the other groups. 

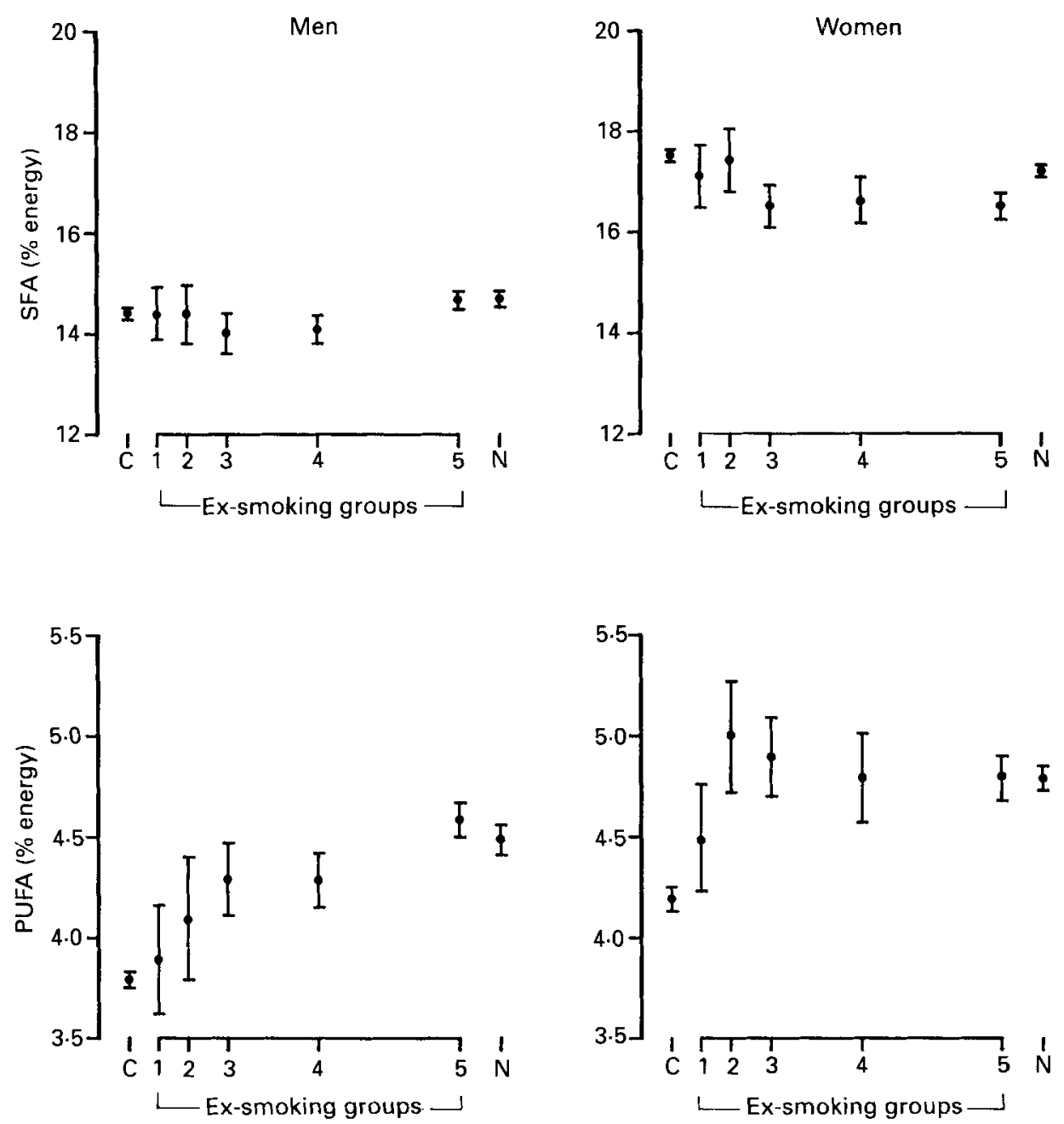

Fig. 1. (contd.). For legend see p. 321.

Results of the discriminant analyses are presented as block diagrams. Fig. 2 shows those individual nutrient variables which discriminate between the current- and never-smokers and which allocate at least some of the ex-smoking groups into the current- or neversmoking categories to a significant extent. More nutrient variables discriminate currentfrom never-smokers for men than for women. The best discriminators for men were fibre $(\mathrm{g} / 4 \cdot 2 \mathrm{MJ})$ and percentage energy from protein, which correctly categorized 74 and $61 \%$ of current-smokers, and 58 and $61 \%$ of never-smokers respectively. For women, fibre $(\mathrm{g} / 4 \cdot 2 \mathrm{MJ})$ provided the best discrimination between the current ( $67 \%$ correct)- and never ( $54 \%$ correct)-smokers. Women who were ex-smokers remained equivalent to currentsmokers with respect to alcohol intake but with respect to fibre intake resembled neversmokers within 6 months of quitting. For men, ex-smokers remained more similar to current-smokers for times varying from 6 months to 3 years depending on the nutrient.

When all the nutrient variables were used to discriminate between the current- and neversmokers (Fig. 3), discrimination was better for men (71\%) than women (65\%). However, 

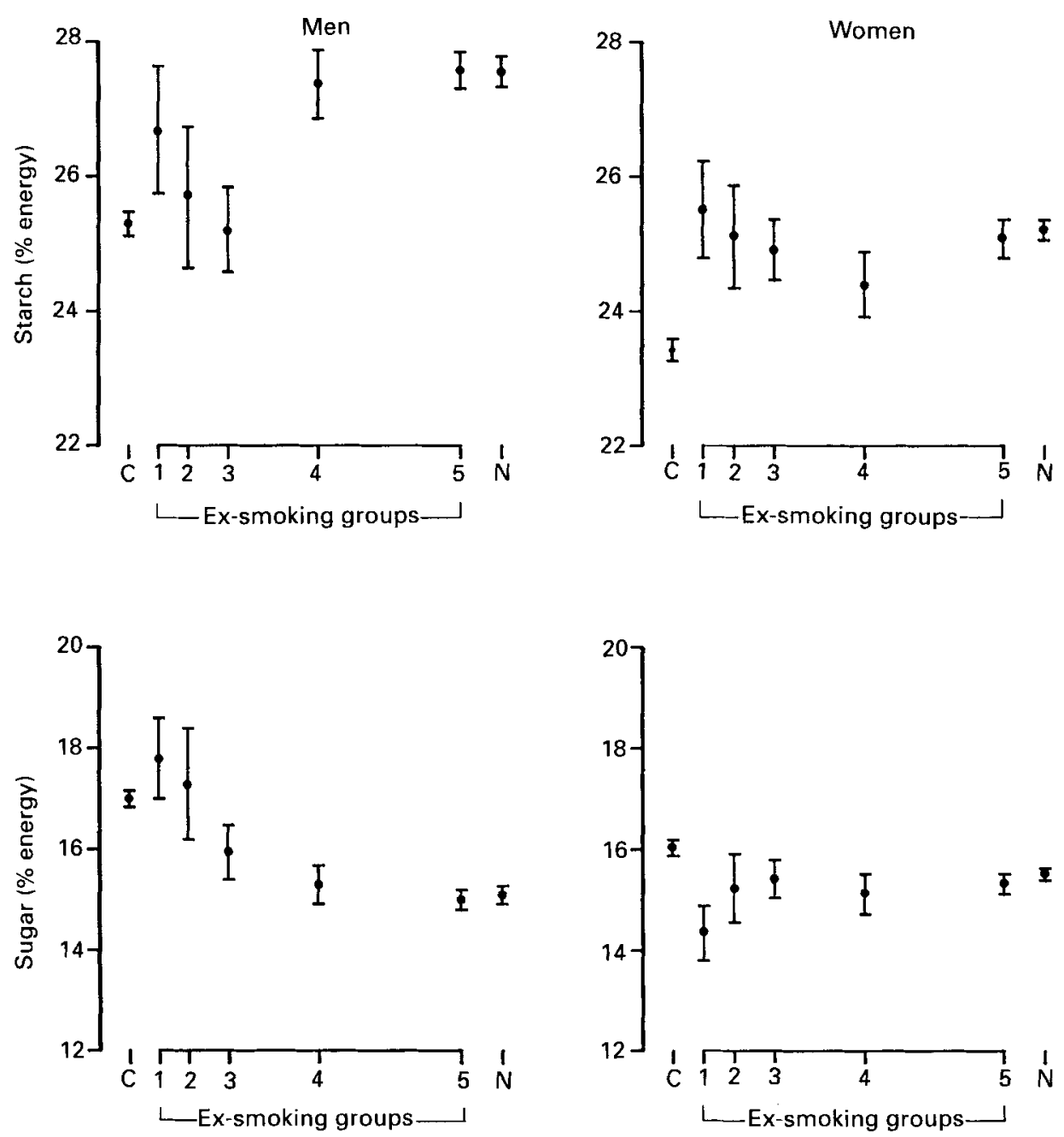

Fig. 1. (contd.). For legend see p. 321.

for both sexes, allocation of the ex-smokers into the current-smoking category was nonsignificant by 6 months after quitting, and they could only be allocated (significantly) into the never-smoking category after 4 years of abstention.

\section{DISCUSSION}

Detailed analysis of diet in ex-smoking groups of different duration has not previously been reported. While the results show that differences do occur between the current-smoking and ex-smoking groups, it is not clear to what extent these differences are a direct consequence of the smoking history or are a result of intrinsic characteristics of the groups, independent of smoking (cohort effect). The higher percentage of 'biochemical deceivers' in the first two ex-smoking groups also suggests that some of them were still smoking, at least occasionally, or chewing nicotine gum (which was not assessed).

Prospective and intervention studies (Gordon et al. 1975; West et al. 1977; Friedman et al. 1979) suggest that quitters differ intrinsically from those who continue to smoke with 

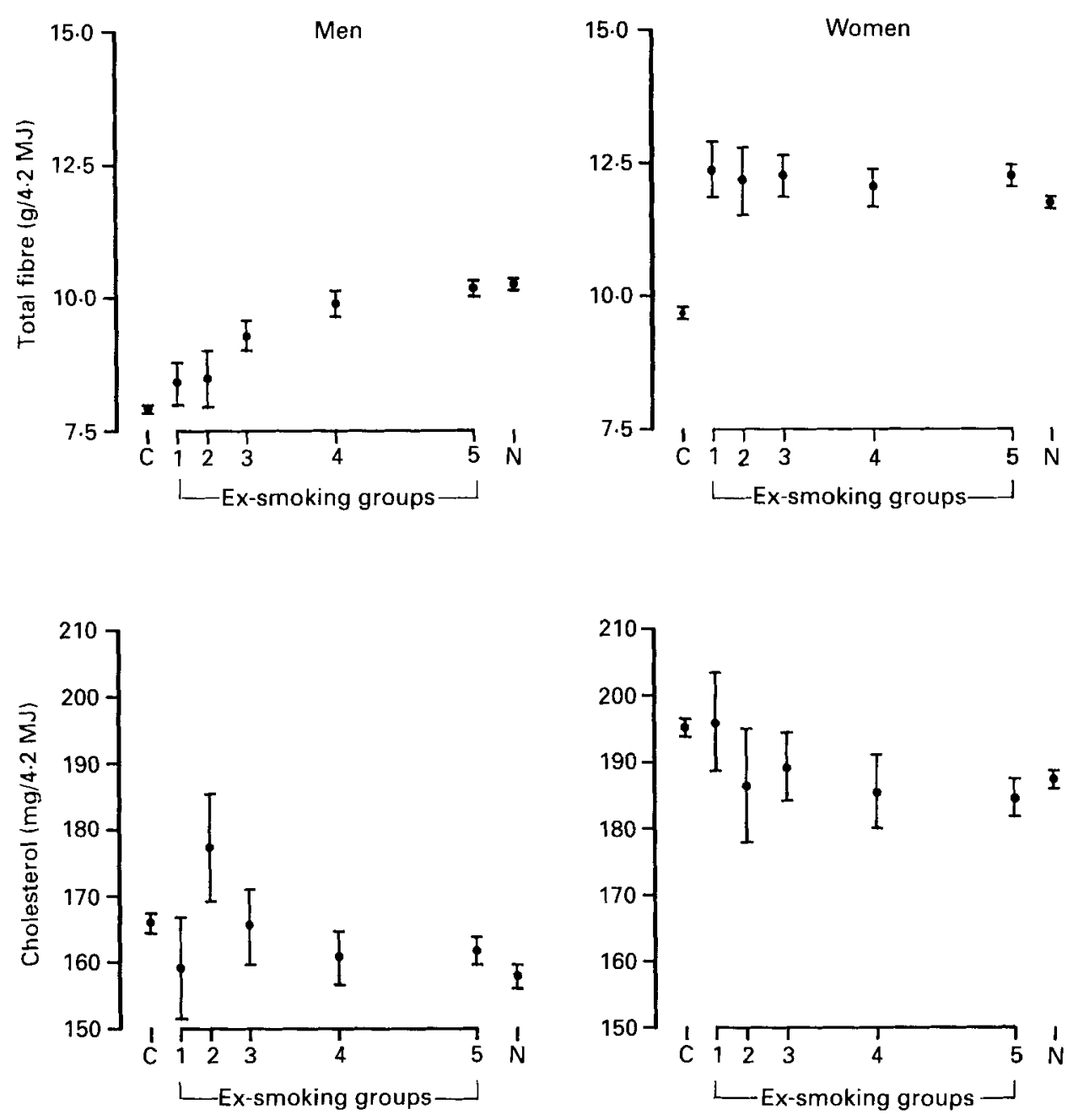

Fig. 1. (contd.). For legend see p. 321.

respect to the age at which they commenced smoking, the number of years smoked and the numbers of cigarettes smoked per d. Ex-smokers are generally likened more to neversmokers in psychological and socio-demographic characteristics and in their risk profile for CHD (West et al. 1977; Kaprio \& Koskenvuo, 1988). In the SHHS population, neversmokers tended to be of higher socio-economic standing (with respect to occupation, education and housing) and have better health knowledge and health-associated activities (such as trying to take more exercise and trying to eat less fat) (C. A. Brown and C. BoltonSmith, unpublished results). While ex-smokers in the SHHS do tend to be better educated and more live in their own homes than do current-smokers, for many other characteristics (such as age and the percentage manually employed) ex-smokers tend to fall between the current- and never-smokers. The lack of any major differences in the median (or mean) age at which smoking commenced, in the number of cigarettes smoked per $d$, or in the total years of smoking, between the current-smokers and the ex-smokers of up to 9 years duration indicates that there are few intrinsic (cohort) differences between the groups with respect to smoking characteristics. While these results contrast with other studies (e.g. 

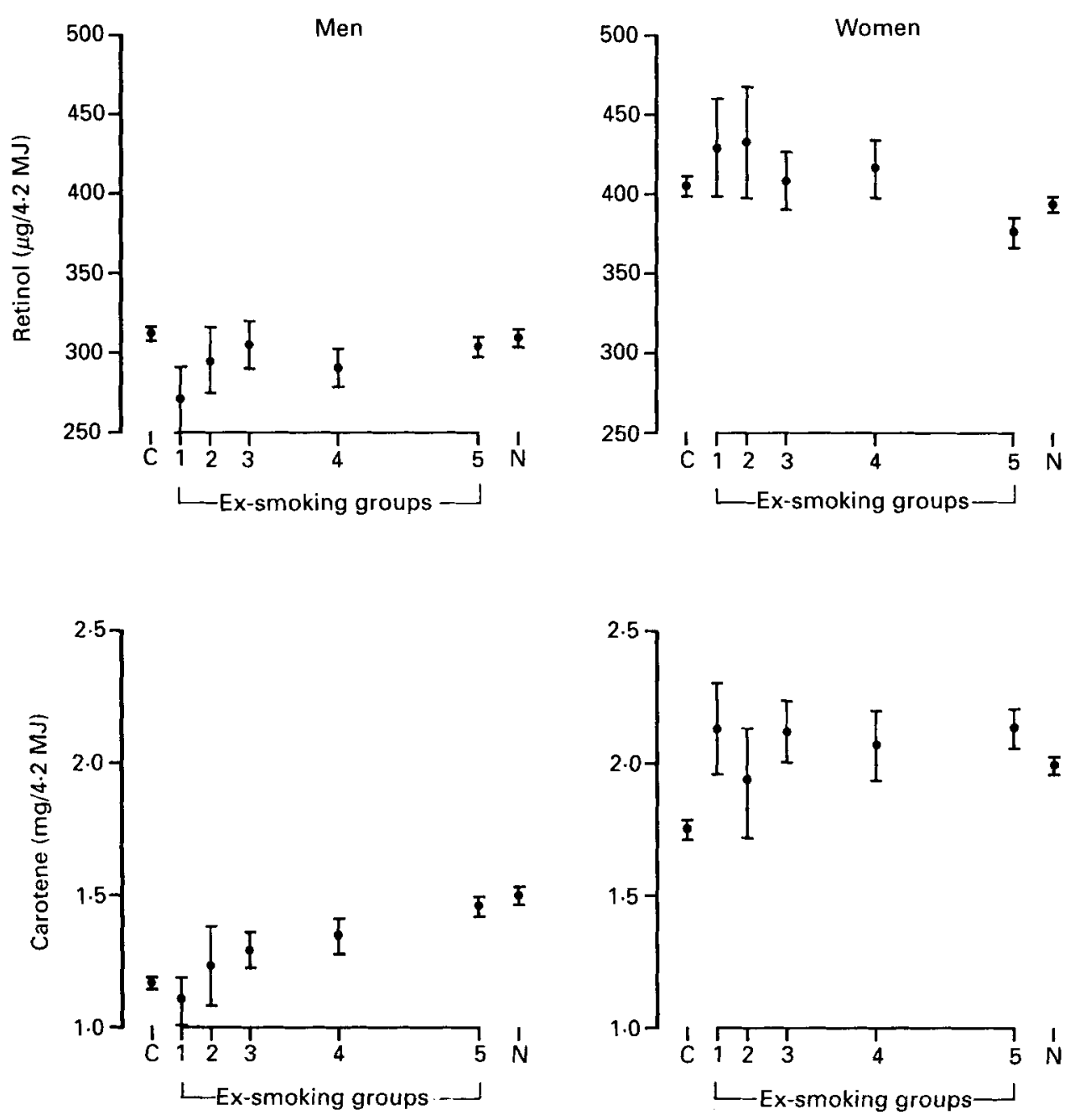

Fig. 1. (contd.). For legend see p. 321.

Friedman et al. 1979), different social pressures may be expected to predominate in different countries, and differences between quitters and non-quitters in withdrawal-clinic follow-up studies (e.g. West et al. 1977) and in CHD patients (e.g. Ockene et al. 1985) are unlikely to be representative of the general population.

Although interpretation of these cross-sectional results in a quasi-longitudinal manner cannot be entirely appropriate, the numerous clear trends in nutrient intakes from currentsmokers through the ex-smoking groups to the never-smokers provides 'circumstantial evidence' to support this approach. Furthermore, there is no evidence from the SHHS to suggest that differential reporting of food frequencies (non-random bias) occurs according to duration of ex-smoking, or between current- and never-smokers.

For both sexes there appears a tendency for the composition and the quality of the diet to be healthier in the ex-smoking groups than in the current-smokers: polyunsaturated fatty acids (PUFA), fibre and the vitamins are higher, and for men only the percentage energy from sugar and alcohol are lower. Heavy coffee consumption ( $\geqslant 6$ cups/d) also tends to be less common as the duration of ex-smoking increases. Kato et al. (1989) found 

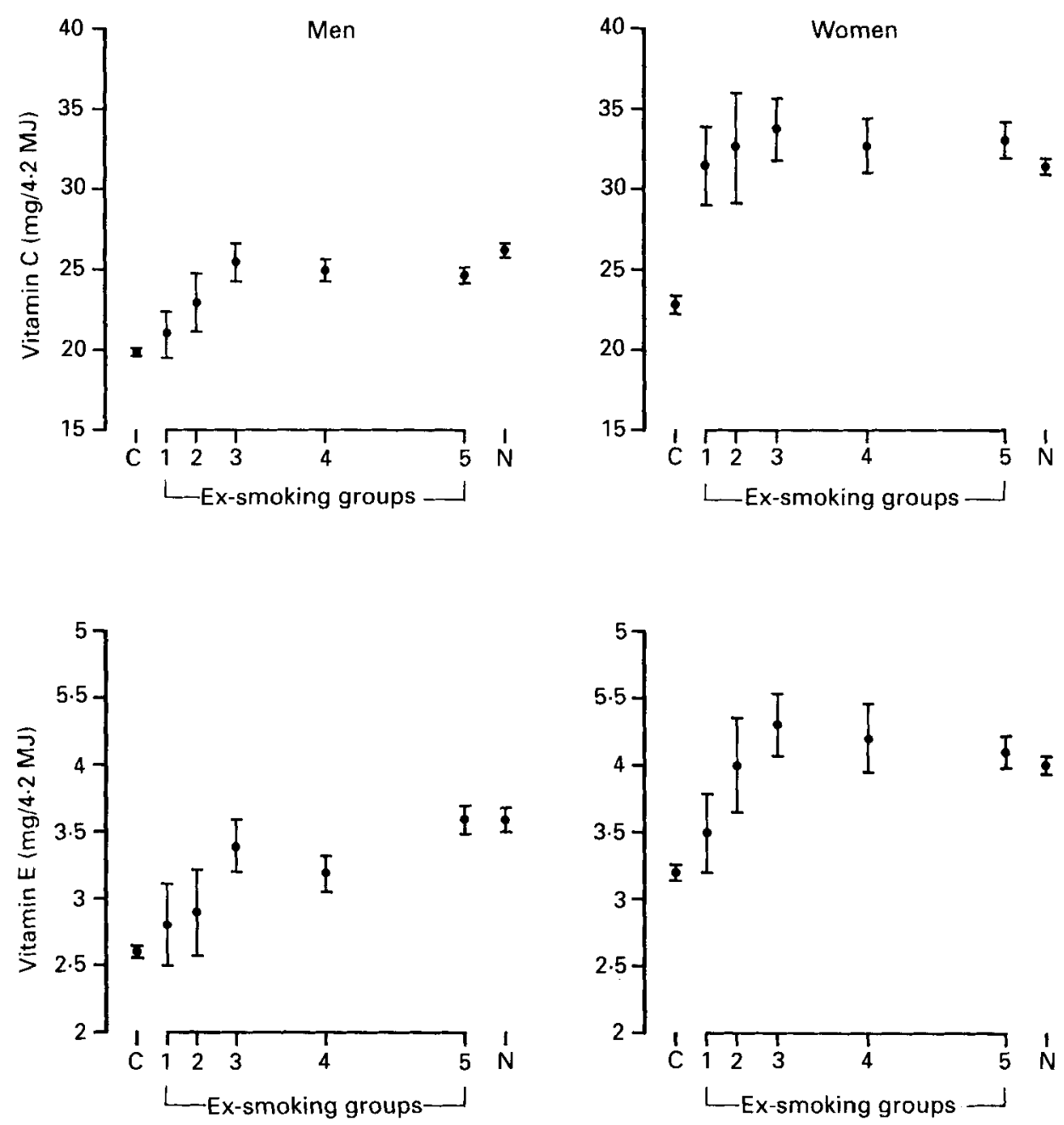

Fig. 1. (contd.). For legend see p. 321.

what can be considered similar results in Japanese ex-smokers, for alcohol and coffee consumption were down and bread and fruit and vegetables were increased in the diets of ex-smokers. Lincoln (1969), in a rather anecdotal letter, reported very similar differences in energy intake between current- and never-smokers, and between current- and ex-smokers as are found here. It is particularly inappropriate that current-smokers and recent ex-smokers have the lowest intake of the antioxidant vitamins, since it is these individuals who probably have the highest requirements for combating free-radical damage (Kallner et al. 1981; Stryker et al. 1988; Bolton-Smith et al. 1991a). The higher intake of vitamin $\mathrm{C}, \mathrm{E}$ and $\beta$-carotene in long-term quitters may be contributing to the overall health benefits which are associated with not smoking.

For men, the diet appears to improve with duration of ex-smoking and reaches approximately the level of nutrient intakes in the never-smokers by 10 years of smoking cessation. The initial rise in the percentage energy from sugar and then progressive fall with duration of ex-smoking may be the result of immediate compensatory eating of sweets instead of smoking, followed by a combination of altered taste preference and the cutting- 
Table 4. Tea and coffee consumption according to smoking group

[Medians and quartile deviations (QD)]

\begin{tabular}{|c|c|c|c|c|c|c|c|c|}
\hline & \multirow[b]{2}{*}{ Current } & \multicolumn{5}{|c|}{ Ex-smokers* } & \multirow[b]{2}{*}{ Never } & \multirow{2}{*}{$\begin{array}{c}\text { Statistical } \\
\text { significance } \\
\text { between } \\
\text { ex-smoking } \\
\text { groups } \\
\left(\chi^{2} \text { test }\right): P\end{array}$} \\
\hline & & 1 & 2 & 3 & 4 & 5 & & \\
\hline \multicolumn{9}{|l|}{ Men } \\
\hline \multicolumn{9}{|l|}{ Coffee } \\
\hline Not drinking $(\%)$ & 30 & 22 & 38 & 29 & 30 & 28 & 28 & NS \\
\hline Drinking $\geqslant 6$ cups $/ \mathrm{d}(\%)$ & 19 & 16 & 19 & 17 & 12 & 8 & 8 & $<0.001$ \\
\hline \multicolumn{9}{|l|}{ No. of cupst $(/ \mathrm{d})$} \\
\hline Median & 4 & 4 & 4 & 3 & 3 & 3 & 3 & - \\
\hline QD & 4 & 3 & 3 & 3 & 3 & 3 & 2 & \\
\hline \multicolumn{9}{|l|}{ Tea } \\
\hline Not drinking $(\%)$ & 12 & 10 & 14 & 13 & 12 & 10 & 10 & NS \\
\hline Drinking $\geqslant 6$ cups $/ d(\%)$ & 32 & 31 & 32 & 29 & 29 & 28 & 22 & NS \\
\hline \multicolumn{9}{|l|}{ No. of cups $\dagger(/ \mathrm{d})$} \\
\hline Median & 2 & 2 & 3 & 2 & 2 & 2 & 2 & - \\
\hline $\mathrm{QD}$ & 6 & 6 & 6 & 7 & 6 & 7 & 7 & \\
\hline \multicolumn{9}{|l|}{ Women } \\
\hline \multicolumn{9}{|l|}{ Coffee } \\
\hline Not drinking $(\%)$ & 28 & 27 & 4 & 21 & 21 & 17 & 27 & $<0.05$ \\
\hline Drinking $\geqslant 6$ cups $/ d(\%)$ & 23 & 13 & 33 & 18 & 16 & 14 & 10 & $<0.05$ \\
\hline \multicolumn{9}{|l|}{ No. of cups $\dagger(/ \mathrm{d})$} \\
\hline Median & 4 & 3 & 5 & 3 & 3 & 3 & 3 & - \\
\hline QD & 4 & 3 & 4 & 3 & 3 & 3 & 2 & \\
\hline \multicolumn{9}{|l|}{ Tea } \\
\hline Not drinking $(\%)$ & 15 & 14 & 26 & 11 & 12 & 15 & 9 & NS \\
\hline Drinking $\geqslant 6$ cups $/ \mathrm{d}(\%)$ & 31 & 25 & 20 & 25 & 24 & 19 & 26 & NS \\
\hline \multicolumn{9}{|l|}{ No. of cupst $(/ \mathrm{d})$} \\
\hline Median & 2 & 8 & 1 & 8 & 8 & 2 & 8 & - \\
\hline QD & 7 & 7 & 3 & 7 & 7 & 6 & 7 & \\
\hline
\end{tabular}

NS, not significant.

* Grouped according to duration of ex-smoking: $1,<6$ months $; 2,6-11$ months; $3,1-4$ years; 4, 5-9 years; $5, \geqslant 10$ years.

$\dagger$ Median no. of cups drunk per d, excluding non-drinkers.

out of sugar to resist weight gain. The higher PUFA, fibre and vitamin intakes could suggest either increasing health awareness and long-term changing of dietary habits, or a cohort effect. It is possible that those people who quit earlier may just be intrinsically more health conscious. However, for women the higher intake of these nutrients (and the decrease in sugar) tends to be most pronounced immediately on quitting smoking and the levels plateau off towards the never-smokers' intakes with further duration of smoking cessation. Two interpretations of these results for women seem possible: either that exsmokers are women with virtually the same characteristics as never-smokers and at no time 'behaved' like current-smokers in any way, or that personal health and social pressures act far more strongly on women than on men such that virtually as soon as they stop smoking concomitantly other healthier life-styles (including dietary) are taken on board. For men, pressures to retain their pre-quitting weights may be less and so less conscious dietary control may be exercised. The lower energy intake for both sexes on quitting and the apparent inverse relationship between energy intake and BMI may be partly due to the 
(a) Men

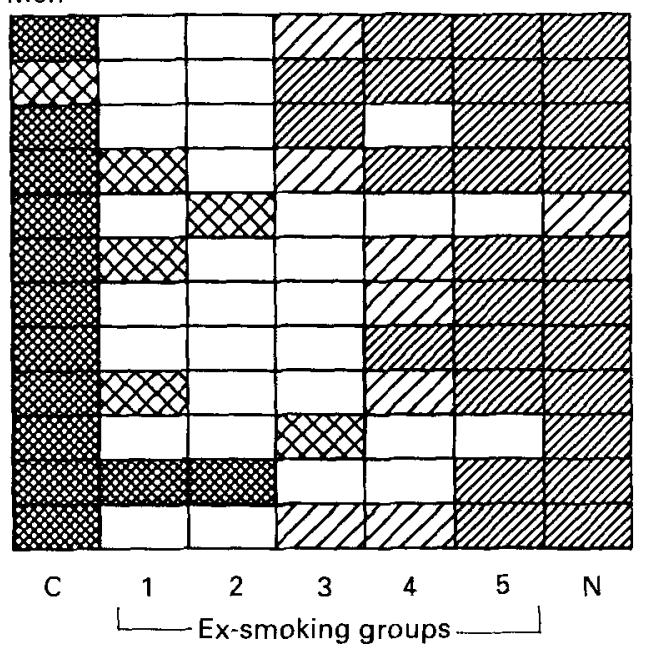

(b) Women

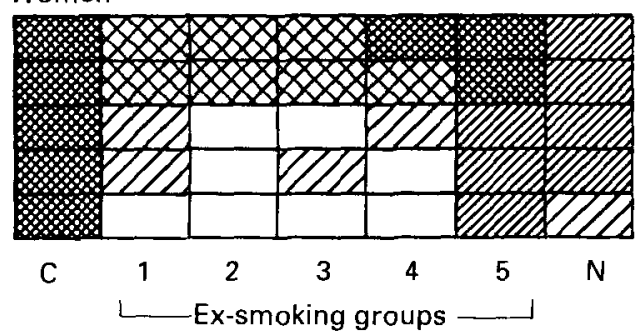

Energy $(\mathrm{MJ} / \mathrm{d})$

Fat $(\mathrm{g} / \mathrm{d})$

Carbohydrate $(\mathrm{g} / \mathrm{d})$

Sugar $(g / d)$

Fibre $(\mathrm{g} / \mathrm{d})$

Fat (\% energy)

Sugar (\% energy)

Starch (\% energy)

Protein (\% energy)

Alcohol (\% energy)

Fibre $(\mathrm{g} / 4.2 \mathrm{MJ})$

PUFA : SFA

Fig. 2. Nutrients whose discriminant factors allocate the ex-smoking groups (1-5) to the current (C)- or never $(\mathrm{N})$ smoking categories with a specificity significantly greater than $50 \%$ by the least significant difference method. (Nutrients not shown gave no significant discrimination between $\mathrm{C}$ - and $\mathrm{N}$-smoking categories.) Ex-smoking groups: $1,<6$ months; $2,6-11$ months; $3,1-4$ years ; $4,5-9$ years; $5, \geqslant 10$ years. PUFA:SFA, polyunsaturated: saturated fat. For details of subjects and groups, see Table 1 and p. 316. $>50 \%$ allocated to C-smoking category $P<0.01 ; \otimes,>50 \%$ allocated to $\mathrm{C}$-smoking category $P<0.05 ; 0,>50 \%$ allocated to $\mathrm{N}$-smoking category $P<0.01 ; \square,>50 \%$ allocated to $\mathrm{N}$-smoking category $P<0.05 ; \square$, No significant allocation to $C$ - or $\mathrm{N}$-smoking category.

metabolic effects of nicotine and nicotine withdrawal, as suggested previously (Wack \& Rodin, 1982). This relationship will be investigated in more detail in a subsequent report, since levels of physical activity must also be considered in the energy equation.

The results of the discriminant analyses using the individual nutrients further illustrated the greater similarity of diets between the smoking groups for women compared with men. Ex-smoking women retained the alcohol consumption pattern of current-smokers, perhaps because alcohol is often disregarded in the energy equation and no other reason for reducing intake is present. Fibre showed a different pattern since ex-smokers immediately had the consumption level of never-smokers. The opposite patterns for these two nutrients could be construed as further evidence against specific cohort effects. However, although it may seem unlikely that the majority of ex-smoking women are people who (regardless of smoking history) consume relatively high-alcohol and high-fibre diets, this pattern is characteristic of the higher social classes (Bolton-Smith et al. 1991 b). 
(a) Men

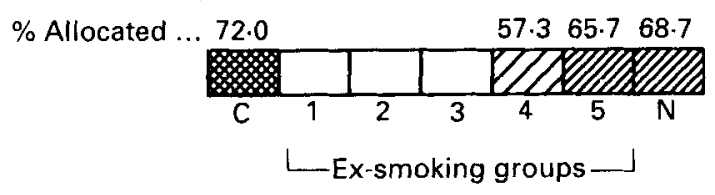

(b) Women

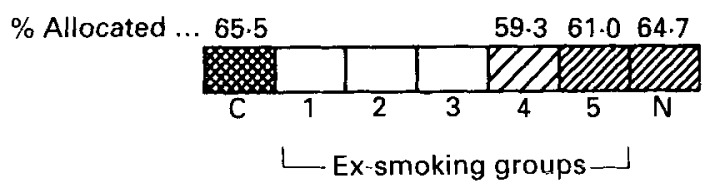

Fig. 3. Allocation of the ex-smoking groups (1-5) to the current (C)- or never (N)-smoking categories, with a specificity significantly greater than $50 \%$ by the least significant difference method, on the basis of the discriminant function for combined nutrient intake. Ex-smoking groups: $1,<6$ months; 2, 6-11 months; 3, 1-4 years; 4, 5-9 years $; 5, \geqslant 10$ years. For details of subjects and groups, see Table 1 and p. $316.8,>50 \%$ allocated to C-smoking category $P<0.01 ;$ 廌, $>50 \%$ allocated to $\mathrm{N}$-smoking category $P<0.01 ; \square,>50 \%$ allocated to $\mathrm{N}$-smoking category $P<0.05 ; \square$, No significant allocation to $\mathrm{C}$ - or $\mathrm{N}$-smoking category.

For men, it appears as if after 1 year of smoking cessation the energy intake and amounts of fat and carbohydrate are similar to never-smokers, but that the percentage contributions of the different nutrients to energy intake do not approximate those of the never-smokers until at least 5 years of cessation. The results of Kato et al. (1989) show similar variation in the time-periods before the patterns of food consumption in the ex-smokers resemble more closely the pattern of the never-smokers.

The discriminant function for the combined nutrients increased the power of the diet to categorize correctly current- and never-smokers for both men and women, and suggests that the diet of ex-smokers of 5 or more years duration is generally similar to that of neversmokers. This time-period is in good agreement with the reported times required for past smokers to lose their excess risk of CHD (e.g. Doll \& Peto, 1976; Rosenberg et al. 1985, 1990). However, it is contended that CHD risk may actually be lower in ex- than in neversmokers, and the 'conventional wisdom' regarding smoking and the risk of CHD is questioned (Seltzer, 1989). Thus, over-interpretation and over-simplification of these results must be avoided. Given the recognized difficulties in assessing diet and nutrient intake (e.g. Cameron \& Van Staveren, 1988), in future the method for classifying smokers is unlikely to change. However, it is plausible that dietary factors contribute to the excess CHD risk of smokers and conversely that if people improve their diet (with respect to fat, fibre and vitamin intakes) on quitting smoking, they may contribute further to their reduction in coronary risk.

M. W. is an Honorary Research Fellow. C. B.-S. is grateful for funding from the British Heart Foundation, and the Scottish Office: Home and Health Department funded the SHHS. Thanks go to Miss Mary Wilson for secretarial assistance. The opinions expressed in this paper are those of the authors alone.

Bolton-Smith, C. \& Milne, A. C. (1991). Food frequency $v$. weighed intake data in Scottish men. Proceedings of the Nutrition Society 50, 35A. 
Bolton-Smith, C., Casey, C. E., Gey, K. F., Smith, W. C. S. \& Tunstall-Pedoe, H. (1991 a). Assessment of antioxidant vitamin intakes using a food frequency questionnaire: validation by biochemical markers in smokers and non-smokers. British Journal of Nutrition 65, 337-346.

Bolton-Smith, C., Smith, W. C. S., Woodward, M. \& Tunstall-Pedoe, H. (1991b). Nutrient intakes of different social class groups: Results from the Scottish Heart Health Study. British Journal of Nutrition 65, 321-335.

Bolton-Smith, C., Woodward, M., Brown, C. A., Smith, W. C. S. \& Tunstall-Pedoe, H. (1991 c). Nutrient intakes from current, ex- and never smokers: Results from the Scottish Heart Health Study. Proceedings of the Nutrition Society 50,36A.

Bolton-Smith, C., Woodward, M., Smith, W. C. S. \& Tunstall-Pedoe, H. (1991d). Dietary and non-dietary predictors of serum total and HDL cholesterol in men and women: Results from the Scottish Heart Health Study. International Journal of Epidemiology 20, 95-104.

Cameron, M. E. \& Van Staveren, W. A. (1988). Manual on Methodology for Food Consumption Studies. New York: Oxford University Press.

Doll, R., Gray, R., Hafner, B. \& Peto, R. (1980). Mortality in relation to smoking: 22 years' observations on female British doctors. British Medical Journal 1, 967-971.

Doll, R. \& Peto, R. (1976). Mortality in relation to smoking: 20 years' observations on male British doctors. British Medical Journal 2, 1525-1536.

Duthie, G. G., Wahle, K. W. J. \& James, W. P. T. (1989). Oxidants, antioxidants and cardiovascular disease. Nutrition Research Reviews 2, 51-62.

Fehily, A. M., Phillips, K. M. \& Yarnell, J. W. G. (1984). Diet, smoking, social class and body mass index in the Caerphilly Heart Disease Study. American Journal of Clinical Nutrition 40, 827-833.

Fischer, M. \& Gordon, T. (1985). The relation of drinking and smoking habits to diet: the Lipid Research Clinic Prevalence Study. American Journal of Clinical Nutrition 41, 623 630.

Friedman, G. D., Siegelaub, A. B., Dales, L. G. \& Seltzer, C. C. (1979). Characteristics predictive of coronary heart disease in ex-smokers before they stopped smoking: comparison with persistent smokers and nonsmokers. Journal of Chronic Disease 32, 175-190.

Fulton, M., Thomson, M., Elton, R. A., Brown, S., Wood, D. A. \& Oliver, M. F. (1988). Cigarette smoking, social class and nutrient intake: Relevance to coronary heart disease. European Journal of Clinical Nutrition $\mathbf{4 2}$, $797-803$.

Gey, K. F., Puska, P., Jordan, P. \& Moser, U. K. (1991). Inverse correlation between plasma vitamin E and mortality from ischaemic heart disease in cross-cultural epidemiology. American Journal of Clinical Nutrition 53, Suppl. 1, 3265-3345.

Gordon, T., Kannel, W. B., Dawber, T. R. \& McGee, D. (1975). Changes associated with quitting cigarette smoking: The Framingham Study. American Heart Journal 90, 322-328.

Gramenzi, A., Gentile, A., Fasoli, M., D’Aranzo, B., Negri, E., Parazzini, E. \& La Vecchia, C. (1989). Smoking and myocardial infarction in women: a case-control study from Northern Italy. Journal of Epidemiology and Community Health 43, 214-217.

Grunberg, N. E. (1982). The effects of nicotine and cigarette smoking on food consumption and taste preferences. Addictive Behaviours 7, 317-331.

Gurr, M. I., Borlak, N. \& Ganatra, S. (1989). Dietary fat and plasma lipids. Nutrition Research Reviews 2, $63-86$.

Hebert, J. R. \& Kabat, G. C. (1990). Differences in dietary intake associated with smoking status. European Journal of Clinical Nutrition 44, 185-193.

Jarvis, M., West, R., Tunstall-Pedoe, H. \& Vesey, C. (1984). An evaluation of the intervention against smoking in the Multiple Risk Factor Intervention Trial. Preventive Medicine 13, 501-509.

Kallner, A. B., Hartmann, D. \& Hornig, D. H. (1981). On the requirements of ascorbic acid in man: steady state turnover and body pool in smokers. American Journal of Clinical Nutrition 34, 1347-1355.

Kaprio, J. \& Koshenvuo, M. (1988). A prospective study of psychological and socio-economic characteristics, health behaviour and morbidity in cigarette smokers prior to quitting compared to persistent smokers and nonsmokers. Journal of Clinical Epidemiology 41, 139-150.

Kato, I., Tominaga, S. \& Suzuki, T. (1989). Characteristics of past smokers. International Journal of Epidemiology 18, $345-354$.

Klesges, R. C., Eck, L. H., Isbell, T. R., Fulliton, W. \& Hanson, C. L. (1990). Smoking status: effects on the dietary intake, physical activity, and body fat of adult men. American Journal of Clinical Nutrition 51, 784-789.

Lincoln, J. E. (1969). Weight gain after cessation of smoking. Journal of the American Medical Association 210 , 1765 .

Morrison, D. F. (1975). Multivariate Statistical Methods, 2nd ed. New York: McGraw-Hill.

Ockene, J. K., Hosmer, D., Rippe, J., Williams, T., Goldberg, R. J., DeCosimo, D., Maher, P. M. \& Dalen, J. E. (1985). Factors affecting cigarette smoking status in patients with ischaemic heart disease. Journal of Chronic Disease 38, 985-994.

Office of Population, Censuses and Surveys (1980). Classification of Occupation. London: H.M. Stationery Office.

Paul, A. A. \& Southgate, D. A. T. (1978). McCance and Widdowson's The Composition of Foods, 4th ed. London: H.M. Stationery Office.

Rosenberg, L., Kaufman, D. W., Helmrich, S. P. \& Shapiro, S. (1985). The risk of myocardial infarction after quitting smoking in men under 55 years of age. New England Journal of Medicine 313, 1511-1514. 
Rosenberg, L., Palmer, J. R. \& Shapiro, S. (1990). Decline in the risk of myocardial infaretion among women who stop smoking. New England Journal of Medicine 322, 213-217.

Seltzer, C. C. (1989). Framingham Study Data and 'established wisdom' about cigarette smoking and coronary heart disease. Journal of Clinical Epidemiology 42, 743-750.

Smith, W. C. S., Tunstall-Pedoe, H., Crombie, I. K. \& Tavendale, R. (1989). Concomitants of excess coronary deaths - major risk factors and life-style findings from 10359 men and women in the Scottish Heart Health Study. Scottish Medical Journal 34, 550-555.

Stryker, W. S., Kaplan, L. A., Stein, E. A., Stampfer, M. J., Sober, A. \& Willett, W. C. (1988). The relation of diet, cigarette smoking and alcohol consumption to plasma beta-carotene and alpha-tocopherol levels. American Journal of Epidemiology 127, 283-296.

Tunstall-Pedoe, H., Smith, W. C. S., Crombie, I. K. \& Tavendale, R. (1989). Coronary risk factors and life-style variation across Scotland. Results from the Scottish Heart Health Study. Scottish Medical Journal 34, 556-560.

US Office on Smoking and Health (1979). Smoking and Health, a Report of the Surgeon General. Washington, DC: US Government Printing Office.

US Office on Smoking and Health (1983). The Health Consequences of Smoking: Cardiovascular Disease, a Report of the Surgeon General. Washington, DC: US Government Printing Office.

Wack, J. T. \& Rodin, J. (1982). Smoking and its effects on body weight and the systems of caloric regulation. American Journal of Clinical Nutrition 35, 366-380.

West, D. W., Graham, S., Swanson, M. \& Wilkinson, G. (1977). Five year follow-up of a smoking withdrawal clinic population. American Journal of Public Health 67, 536-544.

Whichelow, M. J., Golding, J. F. \& Treasure, F. P. (1980). Comparison of some dietary habits of smokers and non-smokers. British Journal of Addiction 83, 295-304.

Willett, W. C., Green, A., Stampfer, M. J., Speizer, F. E., Colditz, G. A., Rosner, B., Monson, R. R., Stason, W. \& Hennekens, C. H. (1987). Relative and absolute excess risk of coronary heart disease among women who smoke cigarettes. New England Journal of Medicine 317, 1303-1309.

Woodward, M. \& Tunstall-Pedoe, H. (1992). An iterative technique for identifying smoking deceivers with application to the Scottish Heart Health Study. Preventive Medicine 21, 88-97.

Yarnell, J. W. G., Fehily, A. M., Milbank, J. E., Sweetnam, P. M. \& Walker, C. L. (1983). A short dietary questionnaire for use in an epidemiological survey. Comparison with weighed dietary records. Human Nutrition: Applied Nutrition 37A, 103-112. 